\title{
Photosensitization of Carbon Nitride Photoelectrodes with CdS: A Novel Architecture with Highly Efficient Photocatalytic Activity
}

\author{
Xiaosong Zhou, ${ }^{1}$ Fei Yang, ${ }^{2}$ Bei Jin,, Tang Xu, ${ }^{1}$ Yaqing Yang, and Xiaohui Yao' \\ ${ }^{1}$ School of Chemistry Science and Technology, and Institute of Physical Chemistry, \\ Zhanjiang Normal University, Zhanjiang 524048, China \\ ${ }^{2}$ The State Key Laboratory of Resources and Environmental Information System, Institute of Geographic Sciences and \\ Natural Resources Research of Chinese Academy of Sciences, Beijing 100101, China
}

Correspondence should be addressed to Fei Yang; yangfei@igsnrr.ac.cn

Received 16 April 2014; Accepted 21 June 2014; Published 6 July 2014

Academic Editor: Leonardo Palmisano

Copyright (C) 2014 Xiaosong Zhou et al. This is an open access article distributed under the Creative Commons Attribution License, which permits unrestricted use, distribution, and reproduction in any medium, provided the original work is properly cited.

CdS with well-defined crystallinity is anchored on carbon nitride photoelectrodes by a successive chemical bath deposition. And the as-synthesized samples were characterized by X-ray diffraction, scanning electron microscopy, transmission electron microscopy, ultraviolet-visible diffuse reflection spectroscopy, X-ray photoelectron spectroscopy, and photoluminescence spectroscopy techniques. The effect of the amount of CdS on the catalytic activity for the degradation of acid Orange II is investigated under visible light irradiation. Results show that the photoelectrodes composed of CdS/CN exhibit much higher catalytic activity than pure CN photoelectrodes. A possible photocatalytic mechanism of the CdS/CN electrodes is proposed under visible light irradiation.

\section{Introduction}

The photocatalysis technique has a promising application prospect in pollutant decomposition and hydrogen production via the generation of $\bullet \mathrm{OH}$ radicals and other oxidative species [1-3]. Although the semiconductor $\mathrm{TiO}_{2}$ is considered as one of the best photocatalysts, its light response range and the photo-efficiency are still limited because of wide band gap $(3.2 \mathrm{eV})[4,5]$. Therefore, to create simple, efficient, and sustainable visible-light photocatalysts is the major challenge in this research field [6]. Recently, polymeric graphitic carbon nitride $\left(\mathrm{g}-\mathrm{C}_{3} \mathrm{~N}_{4}\right)$ was introduced as metalfree photocatalysts for organic photosynthesis; solar energy conversion and sustainable hydrogen production [7] seems to offer new opportunities for solar energy application as covalent carbon nitrides are polymeric, cheap, abundant, and stable materials with easily controllable surface and bulk properties. But the high recombination ratio of photoinduced electron-hole pairs and the very poor response to visible light will hinder the application of $\mathrm{g}-\mathrm{C}_{3} \mathrm{~N}_{4}$ in photocatalysis [8].
Therefore, it is a useful way to expand the light absorption further into the visible range and improve photocatalytic activity by doping with metal or nonmetal species [9-14], synthesizing mesoporous structures [15] or nanorods [16] or coupling with other semiconductors [17-19] and sensitizing by organic dyes [20].

Semiconductor quantum dots (QDs) have been attached to photocatalysts to improve their photoactivity in the visible spectrum. Comparing with other ways, coupling with semiconductors QDs has two unique advantages. On one hand, the band gap of the QDs can be modified by varying the size of the QDs allowing one to tune the visible response of the QDs. On the other hand, QDs can be used to utilize hot electrons or to generate multiple charge carriers with a single high-energy photon [21]. Since Gerischer and Lübke reported that utilizing short band gap semiconductors, such as $\mathrm{CdS}$, as a sensitizer for single crystal $\mathrm{TiO}_{2}$ to improve its photocatalytic activity in visible light region [22], many researchers have explored different approaches to modify large band gap semiconductors $\left(\mathrm{TiO}_{2}, \mathrm{ZnO}\right.$, and $\left.\mathrm{SnO}_{2}\right)$ with 


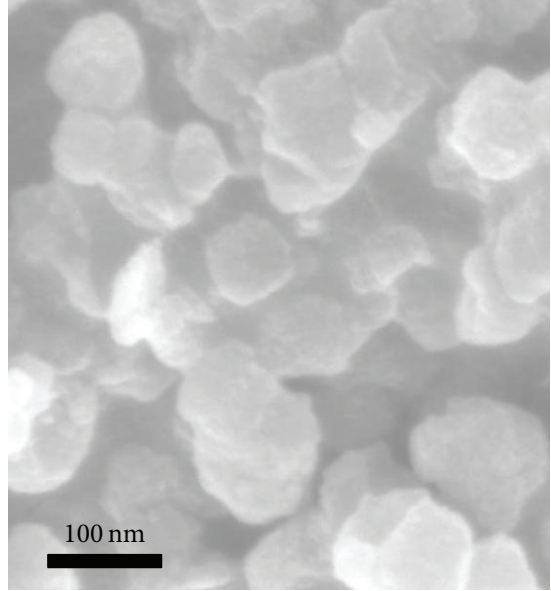

(a)

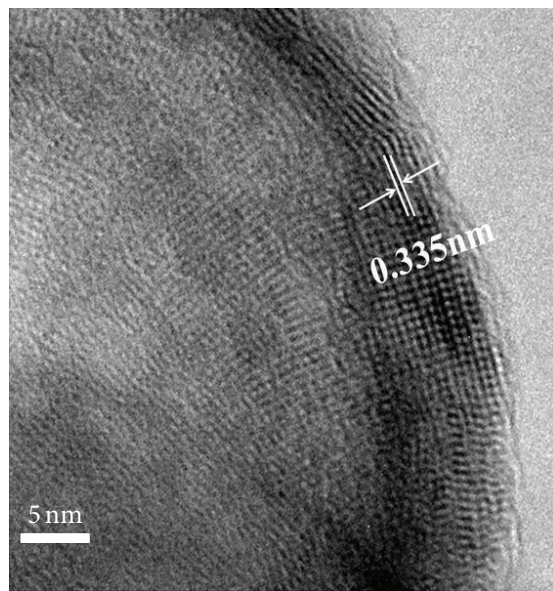

(c)

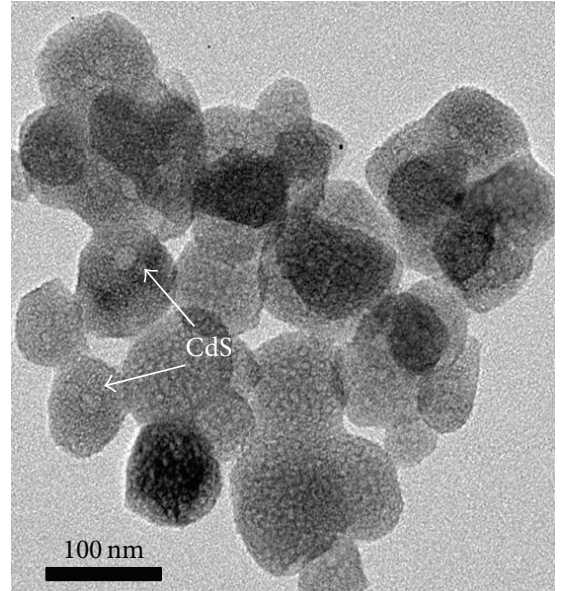

(b)

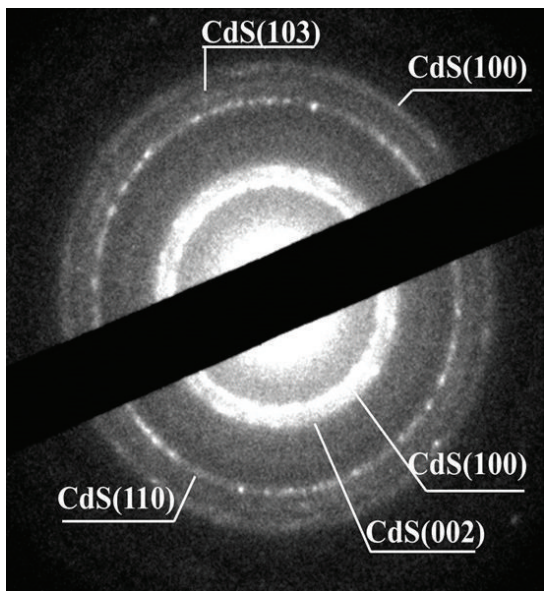

(d)

FIGURE 1: (a) SEM image of CdS/CN-10; (b) TEM image of CdS/CN-10; (c) HRTEM image of CdS/CN-10; (d) SAED pattern of CdS.

a variety of chalogenides [23-26] and probe the excited state charge transfer processes $[27,28]$. Very recently, CdS sensitized $\mathrm{C}_{3} \mathrm{~N}_{4}$ to enhance in both photoactivity and stability [29-31].

In this paper, a high efficient $\mathrm{CdS} / \mathrm{CN}$ photoelectrode by the successive chemical bath deposition (CBD) method is reported. The as-prepared $\mathrm{CdS} / \mathrm{CN}$ photoelectrodes exhibit higher incident photocatalytic activity than those of the pure carbon nitride photoelectrodes under visible light irradiation.

\section{Experimental Section}

2.1. Preparation of Samples. Carbon nitride polymer was prepared by electrodeposition $[32,33]$. In a typical synthesis, a clear Fluorine-doped tin oxide (FTO) glass was used as positive electrode and iron silk was used as negative electrode. The interelectrode separation in all the cases was $2 \mathrm{~mm} .150 \mathrm{~mL}$ of methanol ( $\geqq 99.5 \%)$ and acetonitrile $\left(V_{\text {methanol }}: V_{\text {acetonitrile }}=\right.$ $1: 1)$ mixture was used as solvent and $0.2 \mathrm{M}$ melamine as electrolyte. The typical sample was deposited under an applied potential of $120 \mathrm{~V}$ and kept $1 \mathrm{~h}$ at the room temperature, which was denoted as $\mathrm{CN}$.
CdS was deposited on the carbon nitride electrodes by the successive CBD method. More specifically, the carbon nitride electrodes were immersed in $0.2 \mathrm{M} \mathrm{CdSO}_{4}$ solution for $1 \mathrm{~min}$, rinsed with deionized water, and then immersed in $0.2 \mathrm{M} \mathrm{Na}_{2} \mathrm{~S}$ solution for $1 \mathrm{~min}$ and rinsed again with deionized water. This process was repeated for many cycles and resulted in the formation of $\mathrm{CdS}$ crystallites on the carbon nitride electrodes surface. The degree of surface coverage depends on the number of cycles the deposition repeated, which was denoted as CdS/CN-T (T denotes number of cycles).

2.2. Characterization. X-ray diffraction (XRD) patterns were recorded on an X-ray diffractometer (D/max-IIIA, Japan) by $\mathrm{Cu} \mathrm{Ka}$ radiation at $30 \mathrm{kV}$ and $30 \mathrm{~mA}$ in the angle range of $10-80^{\circ}$. The surface morphology was examined by a scanning electron microscopy (SEM) (LEO1530VP, LEO Company) at an acceleration voltage of $15 \mathrm{kV}$ and a transmission electron microscopy (TEM, JEOL, JEM2010) at $200 \mathrm{kV}$. The UV-vis light absorption spectra were obtained from a Hitachi UV3010 spectrophotometer equipped with an integrating sphere assembly, using the diffuse reflection method and $\mathrm{BaSO}_{4}$ as a reference to measure all the samples. The chemical 
nature of $\mathrm{C}, \mathrm{N}, \mathrm{Cd}$, and $\mathrm{S}$ has been studied by using X-ray photoelectron spectroscopy (XPS) in Krato Axis Ultra DLD spectrometer with $\mathrm{Al} \mathrm{Ka} \mathrm{X}$-ray $(h v=1486.6 \mathrm{eV})$ at $15 \mathrm{kV}$ and $150 \mathrm{~W}$. The binding energy was a reference to Cls line at $284.6 \mathrm{eV}$ for calibration.

2.3. Photoelectrochemical Performances. Photocurrent measurements were carried out in a standard electrodes photoelectrochemical cell by an electrochemical workstation (uECS). The as-prepared samples, platinum-gauze, and $\mathrm{Ag} / \mathrm{AgCl}$ were used as working, counter and reference electrode, respectively. A sodium sulfide solution $(1 \mathrm{M})$ was used as electrolyte. The light for the photocurrent was the filtered light $\left(\lambda>400 \mathrm{~nm}, 150 \mathrm{~mW} \cdot \mathrm{cm}^{-2}\right)$ from a PLS-SXE300UV Xe lamp. The light/dark short circuit photocurrent response under zero bias was recorded by an Agilent digital multimeter.

2.4. Photocatalytic Activity Tests. The photocatalytic activity was measured in a XPAII reactor. The samples $(8 \times 20 \mathrm{~mm})$ were immersed in $10 \mathrm{~mL}$ quartz test tubes containing $4 \mathrm{~mL}$ acid Orange II (OII) $(10 \mathrm{mg} / \mathrm{L})$ in the dark for $1 \mathrm{~h}$ to achieve adsorption equilibrium before irradiation. After that, the visible light $(\lambda>400 \mathrm{~nm})$ photocatalytic experiment was conducted for $2 \mathrm{~h}$. The remaining dye concentrations in the reaction solution were determined using the U3010 spectrophotometer. The whole decomposing process was conducted with sparging air of $10 \mathrm{~mL} / \mathrm{min}$. The degradation ratio of OII can be calculated by $X \%=\left(A_{0}-A\right) / A_{0} \times 100 \%$.

\section{Results and Discussion}

The SEM of CdS/CN electrodes are shown in Figure 1(a). The electrode position method obtained carbon nitride which is irregular spheres with diameters in $70-110 \mathrm{~nm}$. These results are further revealed by TEM. Figure 1(b) clearly shows that the sample has small particle on the surface of carbon nitride with the size of 6 to $10 \mathrm{~nm}$. Figure $1(\mathrm{c})$ is a corresponding high-resolution TEM (HRTEM) image of the small particle on the surface of carbon nitride. It is found that $0.335 \mathrm{~nm}$ fringe of the CdS corresponds to the (220) plane of the cubic phase of CdS (JPCDS 80-0019) [8]. Figure 1(d) presents the selected area electron diffraction (SAED) pattern of the corresponding CdS, and the SAED pattern reveals a cubic phase CdS which is in line with the results obtained from the HRTEM measurement. These results confirmed that the small particle on the surface of carbon nitride is CdS.

The typical XRD patterns of carbon nitride and CdS/CN electrodes are shown in Figure 2. The most intense XRD peak at $27.4^{\circ}$, corresponding to an interlayer distance of $0.326 \mathrm{~nm}$, can be indexed as the (002) peak of the stacking of the conjugated aromatic system. The XRD measurements fully indicate that the as-prepared sample is carbon nitride (Figure 2(a)). The peaks located at $28.3^{\circ}$ are corresponding to cubic phase of CdS (JPCDS 80-0019) [8]. It also indicates that the coexistence of cubic CdS in the composites as additional peaks is observed in the XRD curves of CdS/CN electrodes (Figure 2(b)), which can be assigned to the peaks of cubic CdS. The average particle size calculated by the Scherrer

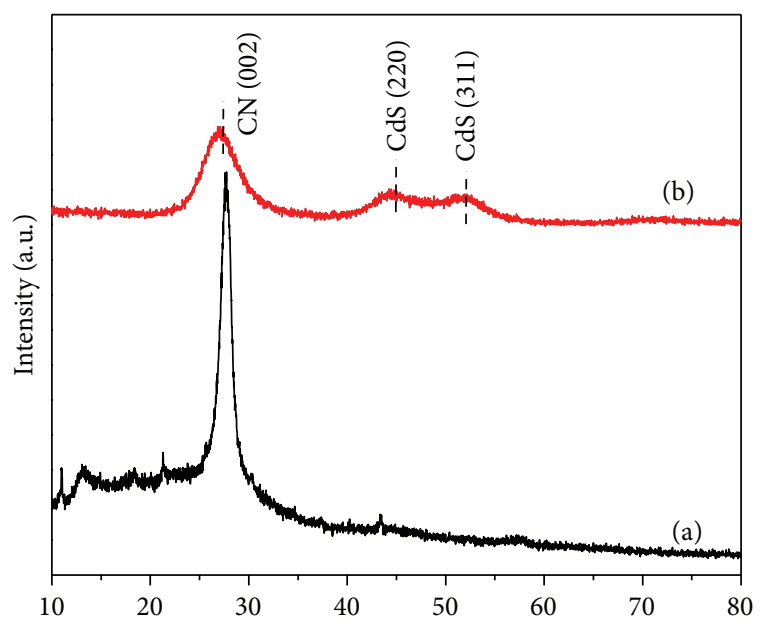

FIGURE 2: XRD patterns of the as-prepared samples: (a) carbon nitride; (b) CdS/CN.

formula from (220) crystal plane of cubic CdS is about $7.8 \mathrm{~nm}$. These results are good consistent with SEM and HRTEM investigation.

Figure 3 shows the high-resolution C1s, N1s, S2p, and Cd3d XPS spectra of CdS/CN-10 electrode, respectively. The Cls and N1s spectra are deconvoluted into various lines, and each of them is associated with a different binding energy (Figures $3(\mathrm{a})$ and $3(\mathrm{~b})$ ), with a $\mathrm{C} / \mathrm{N}$ molar ratio of $0.9[32,33]$. The Cls XPS spectrum in Figure 3(a) can be separated to three peaks at $284.6 \mathrm{eV}, 286.3 \mathrm{eV}$, and $288.4 \mathrm{eV}$, respectively. The peak of $\mathrm{Cls}$ at $284.6 \mathrm{eV}$ is assigned to the $\mathrm{C}-\mathrm{C}$ bond in the turbostratic carbon nitride structure [34], and the peak at $286.3 \mathrm{eV}$ is attributed to the $\mathrm{sp}^{2} \mathrm{C}$ atoms bonded to $\mathrm{N}$ inside the aromatic structure (Figure 3(a)). The peak at $288.4 \mathrm{eV}$ is assigned to the $\mathrm{sp}^{3} \mathrm{C}-\mathrm{N}$ bond of the $\mathrm{sp}^{3}$ bonded composition [34, 35]. The N1s peak is comprised of two components centered at $398.7 \mathrm{eV}$ and $400.1 \mathrm{eV}$ (Figure 3(b)), which are identified as the $\mathrm{C}-\mathrm{N}-\mathrm{C}$ groups and the nitrogen surrounded by an amorphous $\mathrm{N}-(\mathrm{C})_{3}$ network, respectively $[34,36]$. The result shows that the turbostratic carbon nitride structure is similar to the structure of mesoporous carbon nitride reported by Vinu's group [37] and the one in bulk by Gao's group [35]. The $\mathrm{Cd} 3 \mathrm{~d}_{5 / 2}$ and $\mathrm{Cd} 3 \mathrm{~d}_{3 / 2}$ peaks centered at 405.2 and $411.9 \mathrm{eV}$ with a spin-orbit separation of $6.7 \mathrm{eV}$ (Figure 3(c)) can be assigned to $\mathrm{Cd}^{2+}$ of CdS. The S2p peak is observed at $161.8 \mathrm{eV}$ (Figure 3(d)), corresponding to $\mathrm{S}^{2-}$ of CdS. The Cd/S molar ratio is about 1.03 . The content of CdS is approximately 2.53 (wt.\%) in CdS/CN-10 electrode. These results further confirm that the obtained samples are composed of CdS and carbon nitride [38].

In order to study the optical response of $\mathrm{CdS} / \mathrm{CN}$ composites heterojunction, their UV-vis diffuse reflectance spectra (DRS) were measured. Figure 4 showed the DRS of pure carbon nitride and CdS/CN electrodes. The adsorption edge of pure carbon nitride was about $440 \mathrm{~nm}$. While the $\mathrm{CdS} / \mathrm{CN}-$ 5 , CdS/CN-10, and CdS/CN-30 electrodes show high tailing absorbance in the visible light range, the adsorption feature 


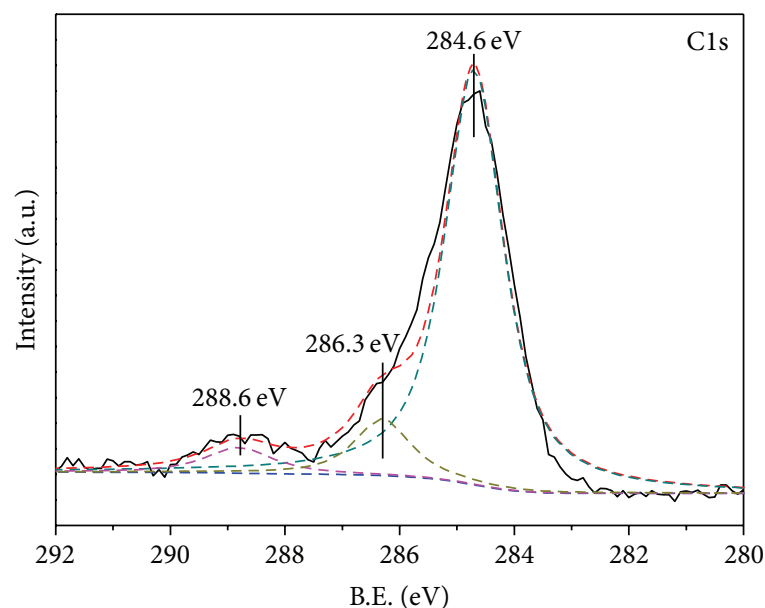

(a)

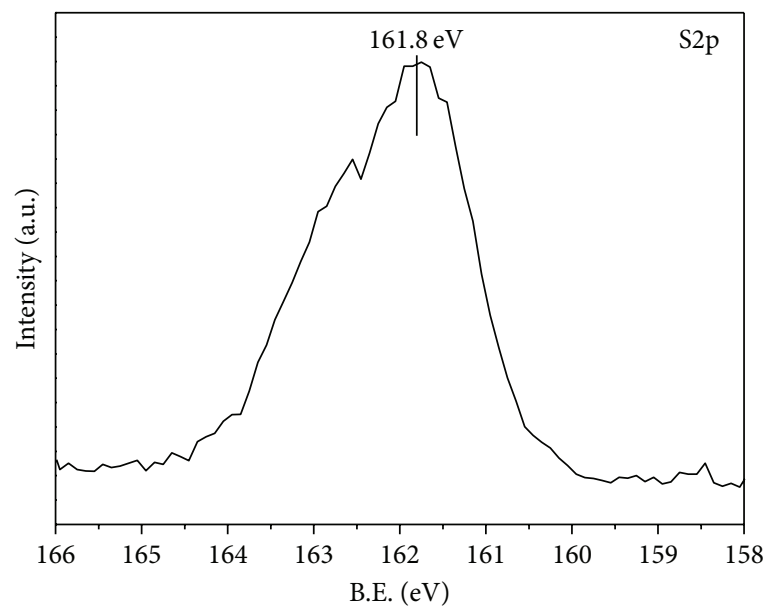

(c)

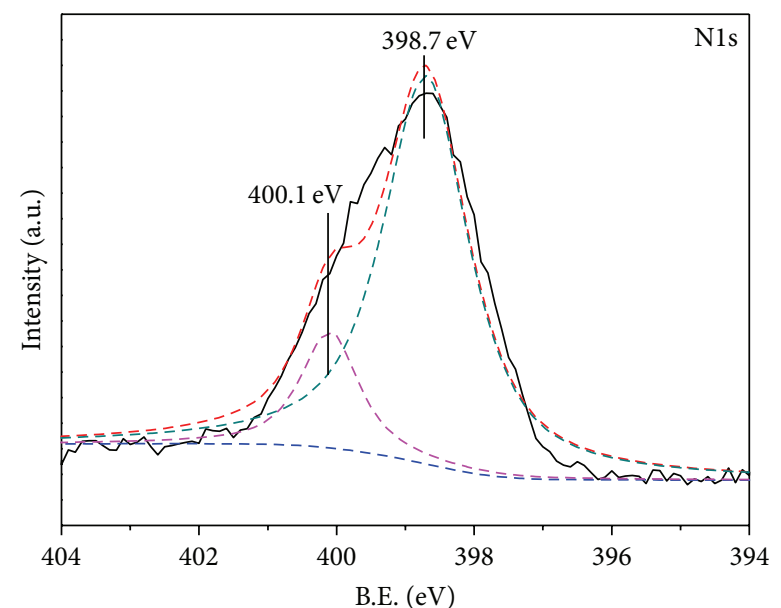

(b)

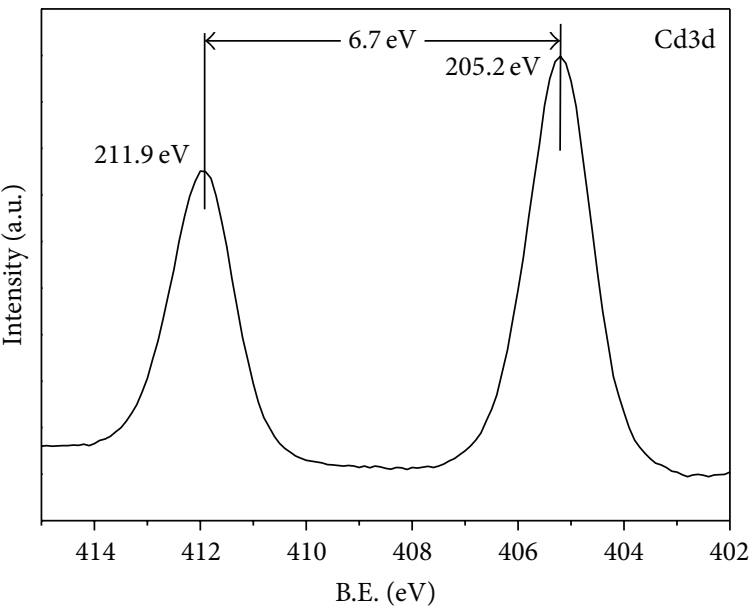

(d)

Figure 3: XPS spectra of the as-obtained sample CdS/CN-10: (a) C1s; (b) N1s; (c) S2p; (d) Cd3d.

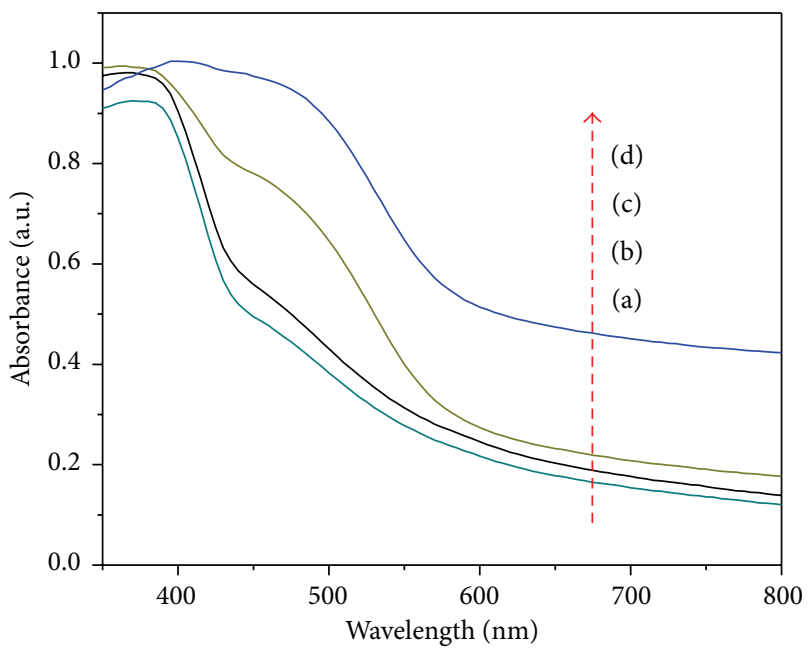

FIGURE 4: UV-vis DRS of the as-prepared samples: (a) carbon nitride; (b) CdS/CN-5; (c) CdS/CN-10; (d) CdS/CN-30. indicates that $\mathrm{CdS} / \mathrm{CN}$ electrodes should be possibly responsive to the visible light.

Figure 5 illustrated the concentration decrease of OII with reaction time photocatalyzed by different samples under visible light. The photodegradation efficiency of carbon nitride was $15 \%$ after $2.5 \mathrm{~h}$ illumination. While the CdS/CN composites showed higher photocatalytic efficiency than pure carbon nitride, and the photodegradation efficiency increases and decreases with the increase of CdS amount in the composites, after $2.5 \mathrm{~h}$ irradiation, the photodegradation efficiency of CdS/CN-10 can nearly reach $100 \%$, which was the highest in all samples.

As reusability of photocatalyst is a key issue for practical application, Figure 6 shows the reusability of CdS/CN-10 electrode for degradation of OII under visible light irradiation. As no obvious decrease of degradation is observed after five runs, the CdS/CN electrodes can be concluded to be stable during the photocatalytic reaction. XPS analysis of the material before and after the experiment (Figure 7) also 


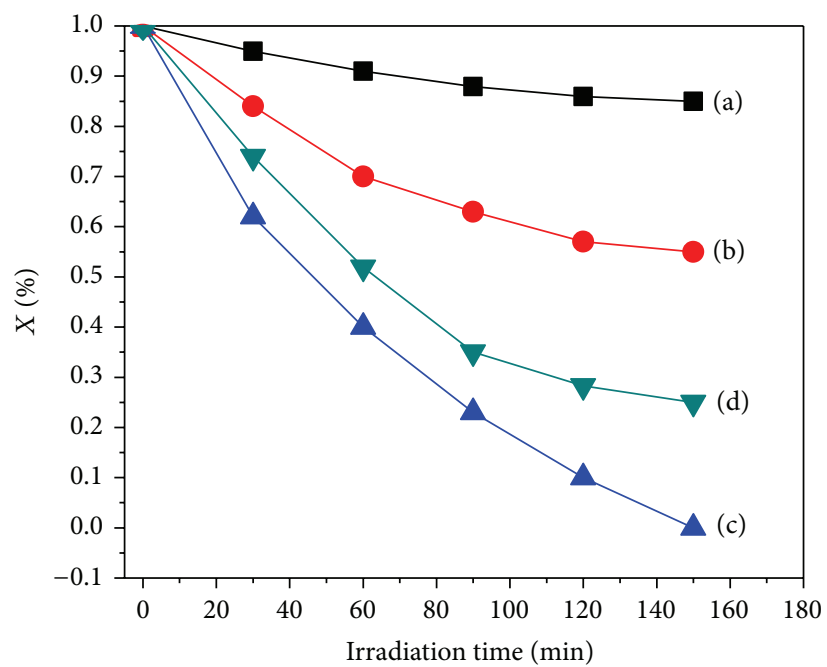

FIGURE 5: Comparison of the photocatalytic activity of the as-prepared samples for the degradation of OII under visible light irradiation: (a) carbon nitride; (b) CdS/CN-5; (c) CdS/CN-10; (d) CdS/CN-30.

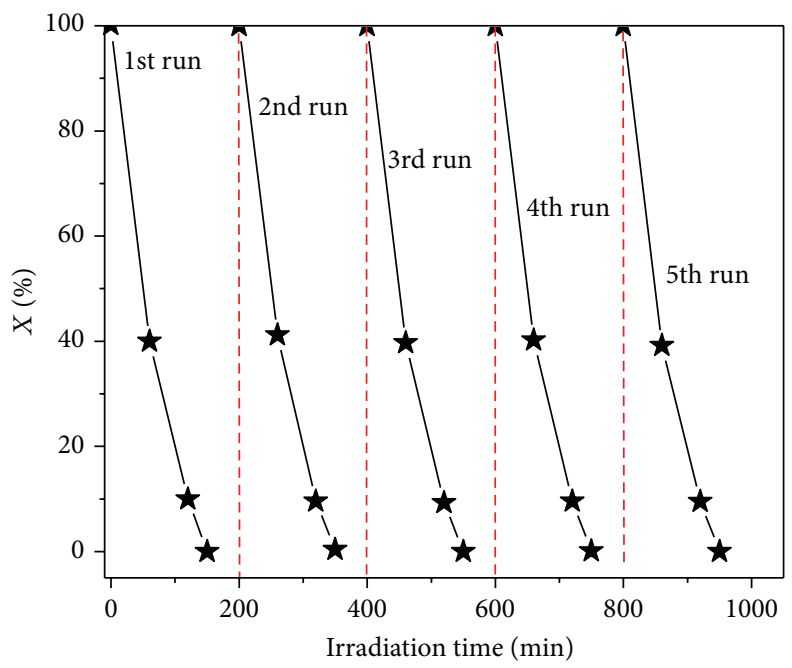

FIGURE 6: Cycling runs for the photocatalytic degradation of OII in the presence of CdS/CN-10 electrode under visible light irradiation.

illustrates that there is no photocorrosion for CdS during the running period. These results suggest that the $\mathrm{CdS} / \mathrm{CN}$ electrodes have excellent reusability stable and can be used as a recyclable photocatalyst.

The photocurrent responses of carbon nitride and $\mathrm{CdS} / \mathrm{CN}$ electrodes under a $0 \mathrm{~V}$ versus $\mathrm{Ag} / \mathrm{AgCl}$ bias are shown in Figure 8. The CdS/CN electrodes exhibit superior performance with greater photocurrent generation efficiency to that of carbon nitride electrode. The photocurrent at first increased and then decreased with increasing deposition cycles. A maximum photocurrent density is obtained from CdS/CN-10 electrode $\left(1.74 \mathrm{~mA} \cdot \mathrm{cm}^{-2}\right)$, which is 6.7 -fold higher than that of the pure carbon nitride electrode $\left(0.26 \mathrm{~mA} \cdot \mathrm{cm}^{-2}\right)$. The increase in photocurrent seen during early CdS deposition cycles is due to increased absorption of light. And then the maximum deposition cycle beyond will decrease the photocurrent of the electrode, which is attributed to completion of CdS growth, cohesion of the aggregates, and saturation in the absorption of photons, resulting in less efficiency in transferring electrons.

Notably, the photocatalytic activities of $\mathrm{CdS} / \mathrm{CN}$ electrodes are significantly enhanced in the presence of CdS distributed over pure carbon nitride electrode, which can be explained from the PL analysis. The PL spectra are widely used to investigate the migration, transfer, and recombination processes of the photogenerated electron-hole pairs in a semiconductor, since PL emission arises from the recombination of free carriers. Figure 9 shows the PL spectra of pure carbon nitride and CdS/CN electrodes excited by $325 \mathrm{~nm}$. From Figure 9, it is clear to see that there is a significant decrease in the PL intensity of CdS/CN electrodes compared to that of pure carbon nitride. A weaker intensity of the peak represents a lower recombination probability of photogenerated charge carriers. Therefore, the CdS dispersed on the surface of 


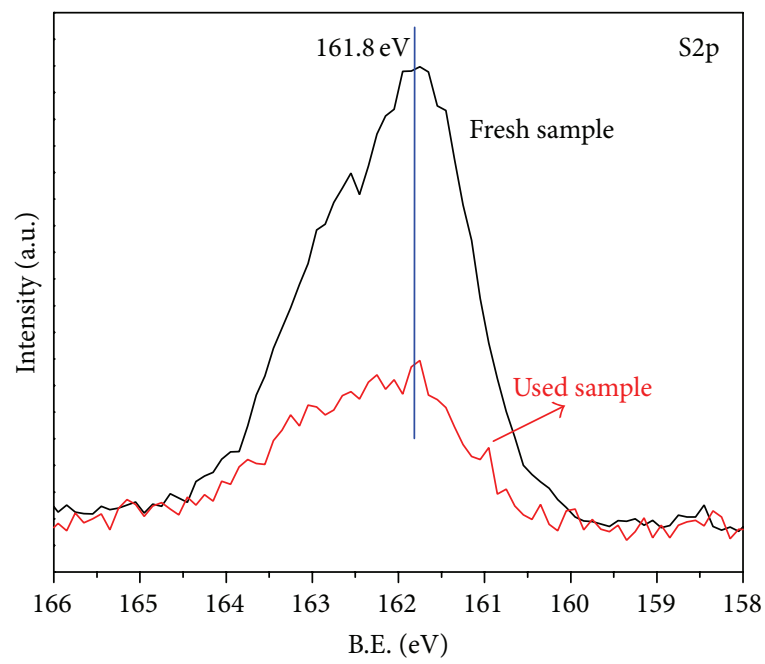

(a)

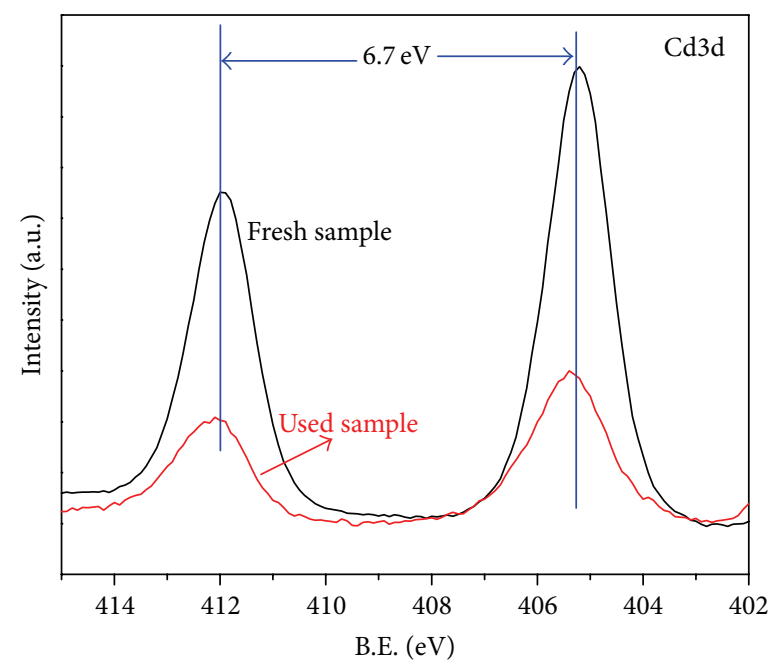

(b)

FIGURE 7: S2p and Cd3d XPS spectra of CdS/CN-10 electrode before and after used in cycling photocatalytic experiments.

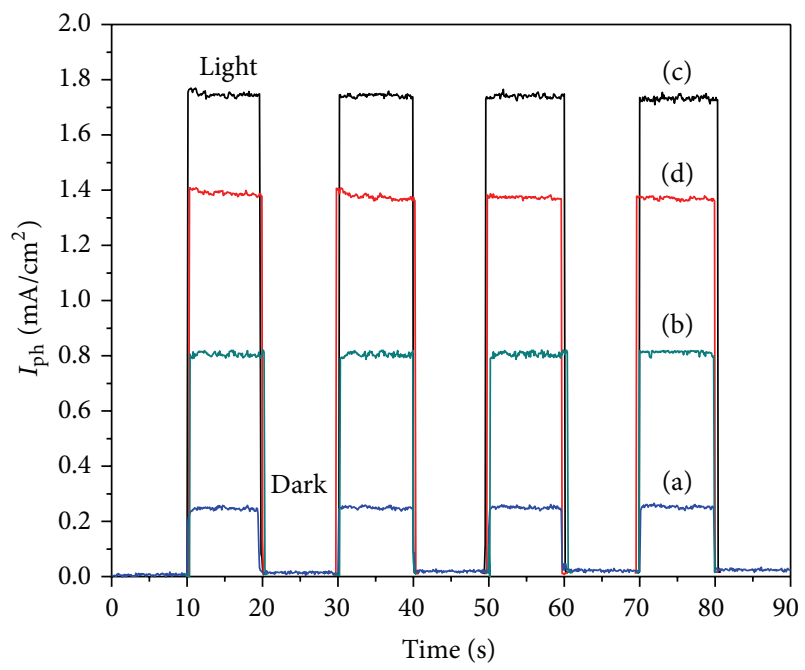

Figure 8: Photocurrent response of the as-prepared samples under visible light illumination: (a) carbon nitride; (b) $\mathrm{CdS} / \mathrm{CN}-5$; (c) CdS/CN-10; (d) CdS/CN-30.

carbon nitride could effectively inhibit the recombination of photogenerated charge carriers, which helps the separation of photogenerated electron-hole pairs in carbon nitride. The significant PL quenching is observed in the $\mathrm{CdS} / \mathrm{CN}$ electrodes as the content of CdS increases. The quenching is due to the photogenerated charge transfer between the CdS and carbon nitride. It can be established that the $\mathrm{CdS} / \mathrm{CN}$ electrodes are very promising for the photocatalysis with satisfying efficiency.

On the basis of the principle of photocurrent responses, $\mathrm{PL}$ data of carbon nitride, and $\mathrm{CdS} / \mathrm{CN}$ electrodes, we depicted the basic structure of the CdS modified with carbon nitride and the main charge-transfer processes between $\mathrm{CdS}$ and carbon nitride after it is activated under visible

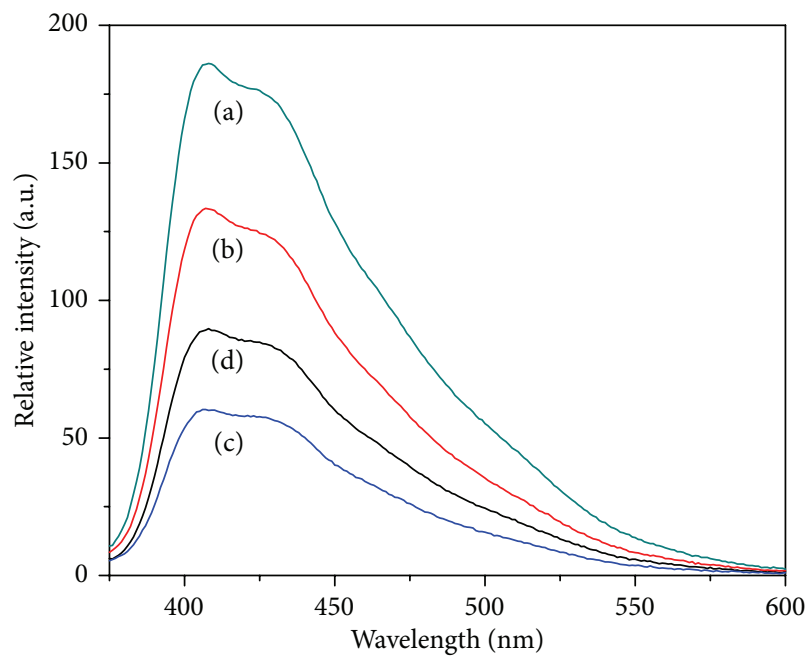

FIGURE 9: Comparison of photoluminescence spectra of the asprepared samples at an excitation wavelength of $325 \mathrm{~nm}$ : (a) carbon nitride, (b) CdS/CN-5, (c) CdS/CN-10, (d) CdS/CN-30.

light irradiation (Figure 10). The overall photoconversion efficiency of a multiband gap semiconductor depends on the position of its conduction and valence bands as well as its geometrical arrangement. For efficient interparticle electron transfer between the semiconductors $\mathrm{CdS}$ and carbon nitride, the conduction band of CdS must be more anodic than the corresponding band of carbon nitride. Density functional theory (DFT) calculations suggest that the $\mathrm{CB}$ and $\mathrm{VB}$ edge potentials of $\mathrm{g}_{-} \mathrm{C}_{3} \mathrm{~N}_{4}$ are at -1.12 and $1.57 \mathrm{eV}$, respectively [7]. However, the $\mathrm{CB}$ and $\mathrm{VB}$ edge potentials of $\mathrm{CdS}$ are at -0.55 and $1.88 \mathrm{eV}$, respectively [39]. These thermodynamic conditions also favor the phenomenon of electron injections, and thus CdS and carbon nitride match very well (Figure 10). Under visible light irradiation, both semiconductors (CdS 


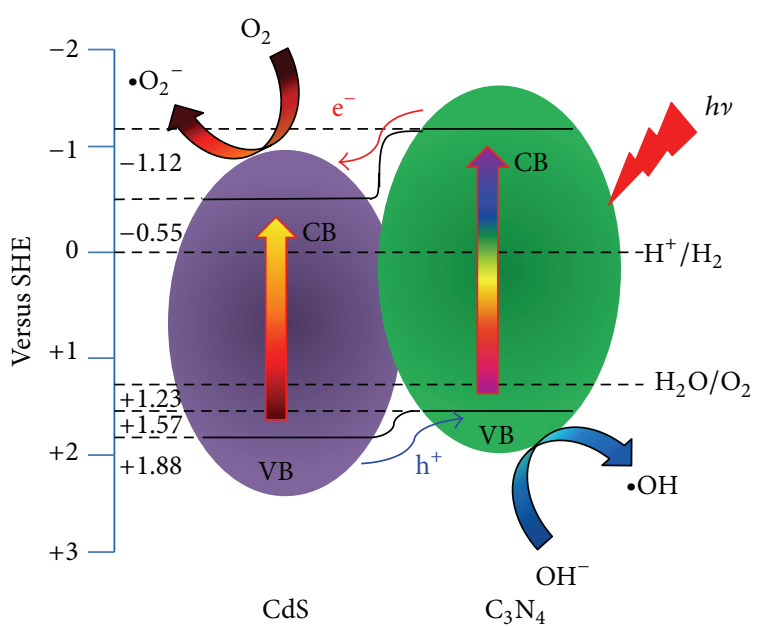

FIGURE 10: Scheme for electron-hole separation and transport at the visible light driven organic-inorganic composites photocatalyst interface and in between $\mathrm{CdS}$ and $\mathrm{C}_{3} \mathrm{~N}_{4}$.

and carbon nitride) are excited. Since the $\mathrm{CB}$ edge potential of carbon nitride is more negative than that of $\mathrm{CdS}$ the photoinduced electrons on carbon nitride particle surfaces transfer easily to CdS via the well-developed interface. Similarly, the photoinduced holes on the CdS surface move to carbon nitride due to the large difference in VB edge potentials. This reduces the probability of electron-hole recombination and leads to a larger amount of electrons on the CdS surface and holes on the carbon nitride surface, respectively, resulting in superior photocatalytic performance of $\mathrm{CdS} / \mathrm{CN}$ electrodes under visible light irradiation.

\section{Conclusion}

We report the synthesis of photocatalyst CdS/CN electrodes by a simple electrodeposition and successive CBD method. This novel architecture leads to better solar light harvesting in the visible light region. The visible light components $(\lambda>$ $400 \mathrm{~nm}$ ) contribute around $1.74 \mathrm{eV}$ of the total photocurrent generated from the CdS/CN-10 electrode. A 6.7-fold enhancement in the degradation of OII is observed between the $\mathrm{CdS} / \mathrm{CN}-10$ electrode and pure carbon nitride. Better visible light absorption and heterojunction structure between the two semiconductors leads to better photoactivity. This approach to design composites photocatalyst will provide a new direction in the field of multijunction solar-cell material.

\section{Conflict of Interests}

The authors declare that there is no conflict of interests regarding the publication of this paper.

\section{Acknowledgments}

This research was supported by Guangdong Natural Science Foundation (S2013040013755) and (S2013010012022), Colleges and Universities in Guangdong Province Science and Technology Innovation Project (2013KJCX0123), and Basic Works Project of Ministry of Science and technology (2012FY111800-5).

\section{References}

[1] M. Shang, W. Z. Wang, S. M. Sun, J. Ren, L. Zhou, and L. Zhang, "Efficient visible light-induced photocatalytic degradation of contaminant by spindle-like PANI/BiVO4," Journal of Physical Chemistry C, vol. 113, no. 47, pp. 20228-20233, 2009.

[2] R. Asahi, T. Morikawa, T. Ohwaki, K. Aoki, and Y. Taga, "Visible-light photocatalysis in nitrogen-doped titanium oxides," Science, vol. 293, no. 5528, pp. 269-271, 2001.

[3] R. Shi, J. Lin, Y. Wang, J. Xu, and Y. Zhu, "Visible-light photocatalytic degradation of $\mathrm{BiTaO} 4$ photocatalyst and mechanism of photocorrosion suppression," Journal of Physical Chemistry C, vol. 114, no. 14, pp. 6472-6477, 2010.

[4] L. Ge, M. Xu, and H. B. Fang, "Synthesis of novel photocatalytic $\mathrm{InVO}_{4}-\mathrm{TiO}_{2}$ thin films with visible light photoactivity," Materials Letters, vol. 61, no. 1, pp. 63-66, 2007.

[5] L. Ge, M. Xu, H. Fang, and M. Sun, "Preparation of $\mathrm{TiO}_{2}$ thin films from autoclaved sol containing needle-like anatase crystals," Applied Surface Science, vol. 253, no. 2, pp. 720-725, 2006.

[6] M. C. Long, W. M. Cai, J. Cai, B. X. Zhou, X. Y. Chai, and $\mathrm{Y} . \mathrm{H}$. Wu, "Efficient photocatalytic degradation of phenol over $\mathrm{Co}_{3} \mathrm{O}_{4} / \mathrm{BiVO}_{4}$ composite under visible light irradiation," Journal of Physical Chemistry B, vol. 110, no. 41, pp. 20211-20216, 2006.

[7] X. Wang, K. Maeda, A. Thomas et al., "A metal-free polymeric photocatalyst for hydrogen production from water under visible light," Nature Materials, vol. 8, no. 1, pp. 76-80, 2009.

[8] Y. Zhang, T. Mori, L. Niu, and J. Ye, "Non-covalent doping of graphitic carbon nitride polymer with graphene: Controlled electronic structure and enhanced optoelectronic conversion," Energy and Environmental Science, vol. 4, no. 11, pp. 4517-4521, 2011.

[9] X. Chen, J. Zhang, X. Fu, M. Antonietti, and X. Wang, "Fe-gC3N4-catalyzed oxidation of benzene to phenol using hydrogen peroxide and visible light," Journal of the American Chemical Society, vol. 131, no. 33, pp. 11658-11659, 2009.

[10] L. Ge, C. C. Han, J. Liu, and Y. F. Li, "Enhanced visible light photocatalytic activity of novel polymeric g- $\mathrm{C}_{3} \mathrm{~N}_{4}$ loaded with Ag nanoparticles," Applied Catalysis A: General, vol. 409-410, pp. 215-222, 2011.

[11] G. Liu, P. Niu, C. Sun et al., "Unique electronic structure induced high photoreactivity of sulfur-doped graphitic C3N4," Journal of the American Chemical Society, vol. 132, no. 33, pp. 11642-11648, 2010.

[12] S. C. Yan, Z. S. Li, and Z. G. Zou, "Photodegradation of rhodamine $B$ and methyl orange over boron-doped $g-\mathrm{C}_{3} \mathrm{~N}_{4}$ under visible light irradiation," Langmuir, vol. 26, no. 6, pp. 3894-3901, 2010.

[13] Y. Zhang, T. Mori, J. H. Ye, and M. Antonietti, "Phosphorusdoped carbon nitride solid: enhanced electrical conductivity and photocurrent generation," Journal of the American Chemical Society, vol. 132, no. 18, pp. 6294-6295, 2010.

[14] Y. Di, X. C. Wang, A. Thomas, and M. Antonietti, "Making metal-carbon nitride hetero-junctions for improved photocatalytic hydrogen evolution with visible light," ChemCatChem, vol. 2, no. 7, pp. 834-838, 2010. 
[15] F. Z. Su, S. C. Mathew, G. Lipner et al., "Mpg- $\mathrm{C}_{3} \mathrm{~N}_{4}$-catalyzed selective oxidation of alcohols using $\mathrm{O}_{2}$ and visible light," Journal of the American Chemical Society, vol. 132, no. 46, pp. 16299-16301, 2010.

[16] X. S Zhou, Y. P Fang, Y. L. Su et al., "Preparation and characterization of poly-hydrogen cyanide nanofibers with high visible light photocatalytic activity," Catalysis Communications, vol. 46, pp. 197-200, 2014.

[17] S. C. Yan, S. B. Lv, Z. S. Li, and Z. G. Zou, "Organic-inorganic composite photocatalyst of $\mathrm{g}-\mathrm{C}_{3} \mathrm{~N}_{4}$ and $\mathrm{TaON}$ with improved visible light photocatalytic activities," Dalton Transactions, vol. 39, no. 6, pp. 1488-1491, 2010.

[18] M. Fu, J. Pi, F. Dong, Q. Duan, and H. Guo, "A costeffective solid-state approach to synthesize g- $\mathrm{C}_{3} \mathrm{~N}_{4}$ coated $\mathrm{TiO}_{2}$ nanocomposites with enhanced visible light photocatalytic activity," International Journal of Photoenergy, vol. 2013, Article ID 158496, 7 pages, 2013.

[19] L. Ge, C. Han, and J. Liu, "Novel visible light-induced g$\mathrm{C}_{3} \mathrm{~N}_{4} / \mathrm{Bi}_{2} \mathrm{WO}_{6}$ composite photocatalysts for efficient degradation of methyl orange," Applied Catalysis B: Environmental, vol. 108-109, pp. 100-107, 2011.

[20] H. J. Yan and H. Yan, "Polymer composites of carbon nitride and poly(3-hexylthiophene) to achieve enhanced hydrogen production from water under visible light," Chemical Communications, vol. 47, no. 14, pp. 4168-4170, 2011.

[21] A. J. Nozik, "Quantum dot solar cells," Physica E: LowDimensional Systems and Nanostructures, vol. 14, no. 1-2, pp. 115-120, 2002.

[22] H. Gerischer and M. Lübke, "A particle size effect in the sensitization of $\mathrm{TiO}_{2}$ electrodes by a CdS deposit," Journal of Electroanalytical Chemistry, vol. 204, no. 1-2, pp. 225-227, 1986.

[23] S. Kohtani, A. Kudo, and T. Sakata, "Spectral sensitization of a $\mathrm{TiO}_{2}$ semiconductor electrode by CdS microcrystals and its photoelectrochemical properties," Chemical Physics Letters, vol. 206, no. 1-4, pp. 166-170, 1993.

[24] R. Vogel, P. Hoyer, and H. Weller, "Quantum-sized PbS, CdS, $\mathrm{Ag} 2 \mathrm{~S}, \mathrm{Sb} 2 \mathrm{~S} 3$, and Bi2S3 particles as sensitizers for various nanoporous wide-bandgap semiconductors," Journal of Physical Chemistry, vol. 98, no. 12, pp. 3183-3188, 1994.

[25] L. M. Peter, K. G. U. Wijayantha, D. J. Riley, and J. P. Waggett, "Band-edge tuning in self-assembled layers of Bi2S3 nanoparticles used to photosensitize nanocrystalline $\mathrm{TiO}_{2}$," Journal of Physical Chemistry B, vol. 107, no. 33, pp. 8378-8381, 2003.

[26] A. Zaban, O. I. Mićić, B. A. Gregg, and A. J. Nozik, "Photosensitization of nanoporous $\mathrm{TiO}_{2}$ electrodes with InP quantum dots," Langmuir, vol. 14, no. 12, pp. 3153-3156, 1998.

[27] J. E. Evans, K. W. Springer, and J. Z. Zhang, "Femtosecond studies of interparticle electron transfer in a coupled CdS- $-\mathrm{TiO}_{2}$ colloidal system," The Journal of Chemical Physics, vol. 101, no. 7, pp. 6222-6225, 1994.

[28] I. Robel, M. Kuno, and P. V. Kamat, "Size-dependent electron injection from excited CdSe quantum dots into $\mathrm{TiO}_{2}$ nanoparticles," Journal of the American Chemical Society, vol. 129, no. 14, pp. 4136-4137, 2007.

[29] S. W. Cao, Y. Yuan, J. Fang et al., "In-situ growth of CdS quantum dots on $\mathrm{g}^{-} \mathrm{C}_{3} \mathrm{~N}_{4}$ nanosheets for highly efficient photocatalytic hydrogen generation under visible light irradiation," International Journal of Hydrogen Energy, vol. 38, no. 3, pp. 1258-1266, 2013.

[30] J. Fu, B. Chang, Y. Tian, F. Xi, and X. Dong, "Novel C3N4CdS composite photocatalysts with organic-inorganic heterojunctions: In situ synthesis, exceptional activity, high stability and photocatalytic mechanism," Journal of Materials Chemistry A, vol. 1, no. 9, pp. 3083-3090, 2013.

[31] L. Ge, F. Zuo, J. Liu et al., "Synthesis and efficient visible light photocatalytic hydrogen evolution of Polymeric g-C 3N 4 coupled with CdS quantum dots," Journal of Physical Chemistry C, vol. 116, no. 25, pp. 13708-13714, 2012.

[32] X. S. Zhou, F. Peng, H. J. Wang, H. Yu, and Y. Fang, "Carbon nitride polymer sensitized $\mathrm{TiO}_{2}$ nanotube arrays with enhanced visible light photoelectrochemical and photocatalytic performance," Chemical Communications, vol. 47, no. 37, pp. 1032310325, 2011.

[33] X. Zhou, B. Jin, L. Li et al., "A carbon nitride/TiO $/ \mathrm{T}_{2}$ nanotube array heterojunction visible-light photocatalyst: synthesis, characterization, and photoelectrochemical properties," Journal of Materials Chemistry, vol. 22, no. 34, pp. 17900-17905, 2012.

[34] Q. Lv, C. Cao, C. Li et al., "Formation of crystalline carbon nitride powder by a mild solvothermal method," Journal of Materials Chemistry, vol. 13, no. 6, pp. 1241-1243, 2003.

[35] Y. Qiu and L. Gao, "Chemical synthesis of turbostratic carbon nitride, containing C-N crystallites, at atmospheric pressure," Chemical Communications, vol. 18, no. 18, pp. 2378-2379, 2003.

[36] Q. Guo, Y. Xie, X. Wang, S. Zhang, T. Hou, and S. Lv, "Synthesis of carbon nitride nanotubes with the $\mathrm{C}_{3} \mathrm{~N}_{4}$ stoichiometry via a benzene-thermal process at low temperatures," Chemical Communications, vol. 10, no. 1, pp. 26-27, 2004.

[37] A. Vinu, K. Ariga, T. Mori et al., "Preparation and characterization of well-ordered hexagonal mesoporous carbon nitride," Advanced Materials, vol. 17, no. 13, pp. 1648-1652, 2005.

[38] J. Zhu, D. Yang, J. Geng, D. Chen, and Z. Jiang, "Synthesis and characterization of bamboo-like $\mathrm{CdS} / \mathrm{TiO}_{2}$ nanotubes composites with enhanced visible-light photocatalytic activity," Journal of Nanoparticle Research, vol. 10, no. 5, pp. 729-736, 2008.

[39] X. Yong and M. A. A. Schoonen, "The absolute energy positions of conduction and valence bands of selected semiconducting minerals," American Mineralogist, vol. 85, no. 3-4, pp. 543-556, 2000 . 

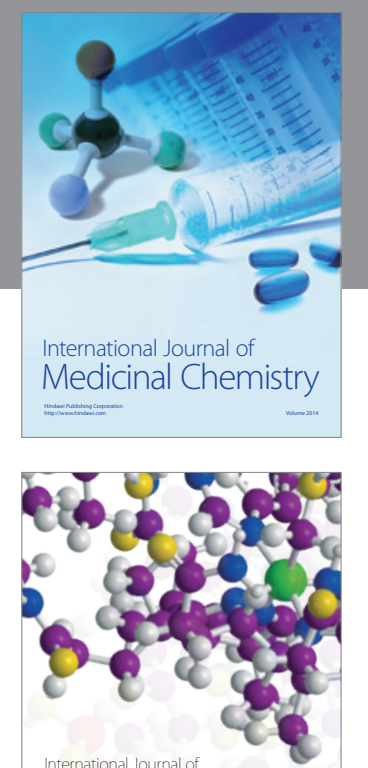

\section{Carbohydrate} Chemistry

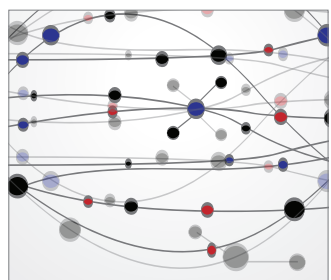

The Scientific World Journal
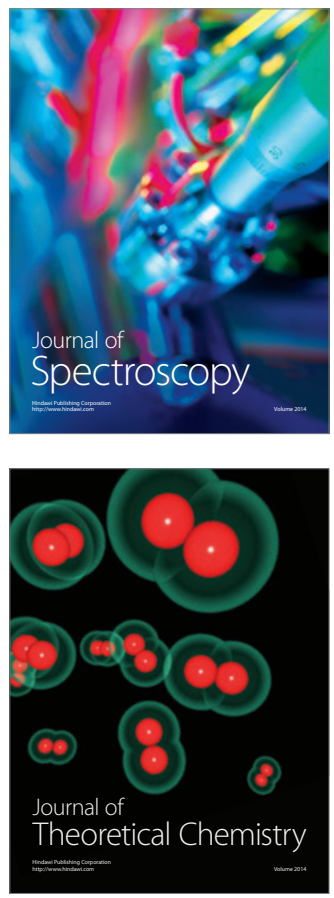
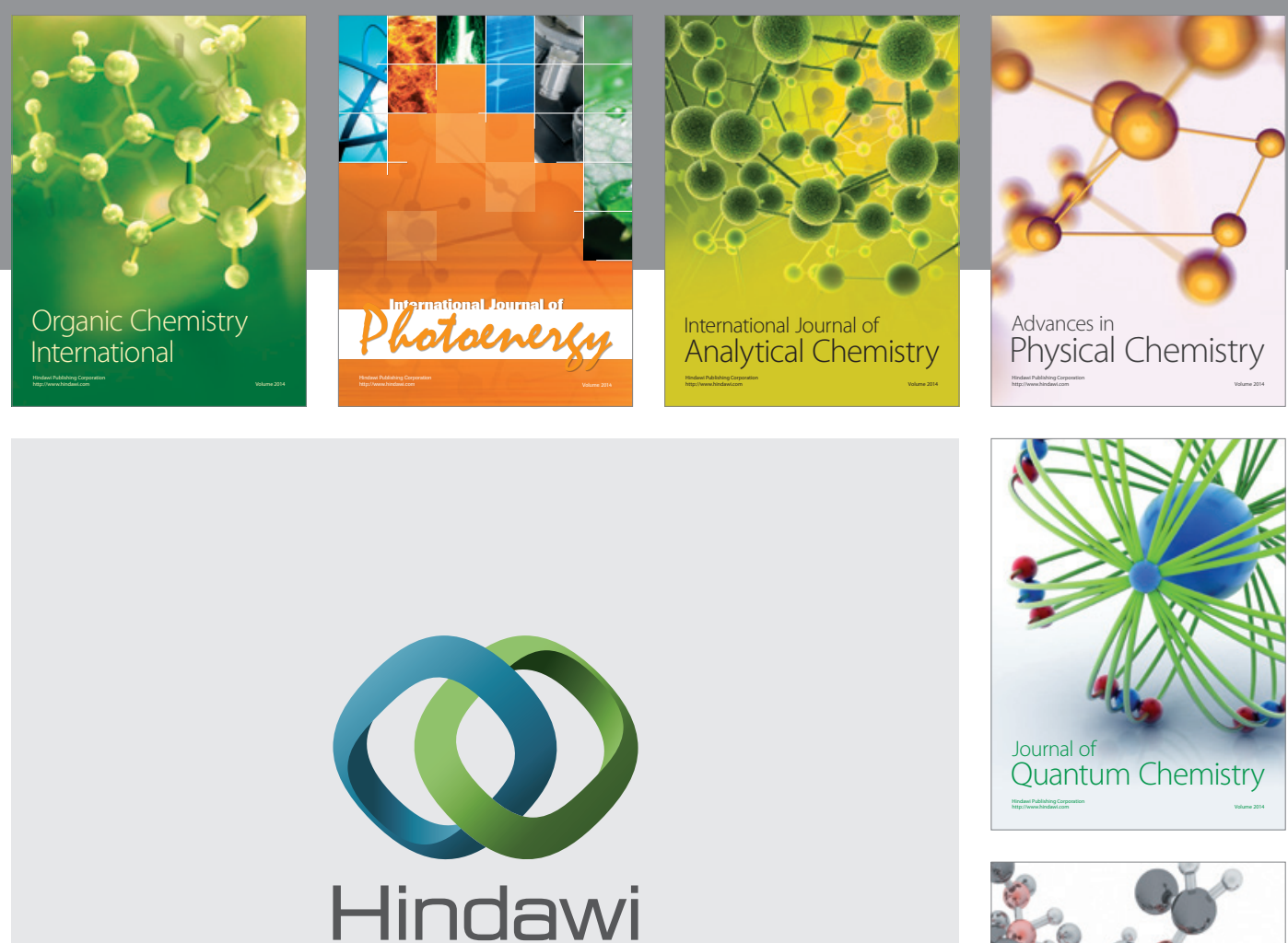

Submit your manuscripts at

http://www.hindawi.com

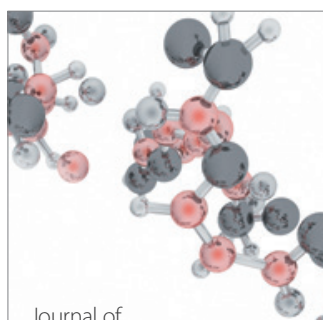

Analytical Methods

in Chemistry

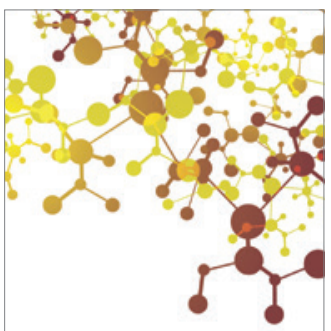

Journal of

Applied Chemistry

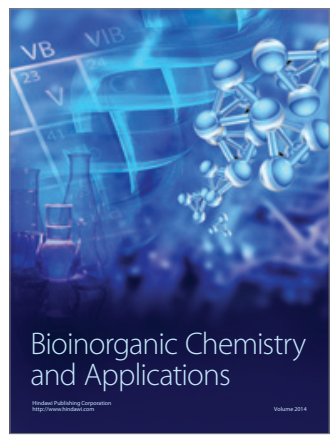

Inorganic Chemistry
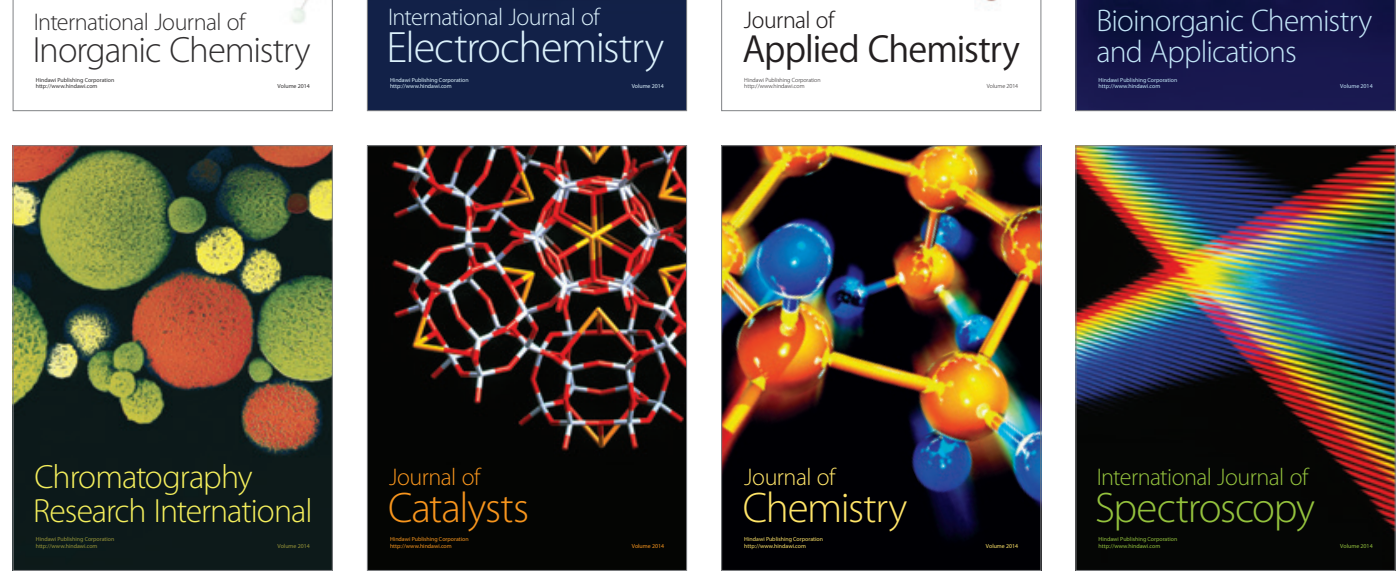